\title{
Actinium Ac 225-FPI-1434
}

National Cancer Institute

\section{Source}

National Cancer Institute. Actinium Ac 225-FPI-1434. NCI Thesaurus. Code C158815.

A radioimmunoconjug ate consisting of the humanized monoclonal antibody lintuzumab conjug ated to the alpha-emitting radioisotope actinium Ac 225 with potential antineoplastic activity. The monoclonal antibody moiety of actinium Ac 225 lintuzumab specifically binds to the cell surface antigen CD33 antigen, delivering a cytotoxic dose of alpha radiation to cells expressing CD33. CD33 is a cell surface antigen expressed on normal non-pluripotent hematopoietic stem cells and overexpressed on myeloid leukemia cells. 